\title{
Perioperative comparison of video-assisted thoracic surgery and open lobectomy for pT1-stage non-small cell lung cancer patients in China: a multi-center propensity score-matched analysis
}

\author{
Jinming $\mathrm{Xu}^{1}$, Heng $\mathrm{Ni}^{1}$, Yihe $\mathrm{Wu}^{1}$, Jinlin $\mathrm{Cao}^{1}$, Xingpeng $\mathrm{Han}^{2}$, Lunxu Liu ${ }^{3}$ Xiangning $\mathrm{Fu}^{4}, \mathrm{Yin} \mathrm{Li}^{5}$, \\ Xiaofei $\mathrm{Li}^{6}$, Lin $\mathrm{Xu}^{7,8}$, Yang Liu', Heng Zhao ${ }^{10}$, Deruo Liu ${ }^{11}$, Xin Peng ${ }^{12}$, Jian $\mathrm{Hu}^{1}$ \\ ${ }^{1}$ Department of Thoracic Surgery, the First Affiliated Hospital, Zhejiang University School of Medicine, Hangzhou, China; ${ }^{2}$ Department of Thoracic \\ Surgery, Tianjin Chest Hospital, Tianjin, China; ${ }^{3}$ Department of Thoracic Surgery, West China Hospital, Sichuan University, Chengdu, China; \\ ${ }^{4}$ Department of Thoracic Surgery, Tongji Hospital, Tongji Medical College, Huazhong University of Science and Technology, Wuhan, China; \\ ${ }^{5}$ Department of Thoracic Surgery, Henan Cancer Hospital, Zhengzhou, China; ${ }^{6}$ Department of Thoracic Surgery, Tangdu Hospital, Fourth Military \\ Medical University, Xi'an, China; ${ }^{7}$ Department of Thoracic Surgery, Nanjing Medical University Affiliated Cancer Hospital, Cancer Institute of \\ Jiangsu Province, Nanjing, China; ${ }^{8}$ Jiangsu Key Laboratory of Molecular and Translational Cancer Research, Cancer Institute of Jiangsu Province, \\ Nanjing, China; ${ }^{9}$ Department of Thoracic Surgery, Chinese People's Liberation Army General Hospital, Beijing, China; ${ }^{10}$ Department of Thoracic \\ Surgery, Shanghai Chest Hospital, Shanghai, China; ${ }^{11}$ Department of Thoracic Surgery, China-Japan Friendship Hospital, Beijing, China; ${ }^{12}$ Medical \\ Affairs, Linkdoc Technology Co. Ltd., Beijing, China \\ Contributions: (I) Conception and design: J Xu, J Hu; (II) Administrative support: J Hu; (III) Provision of study materials or patients: X Han, L Liu, X \\ Fu, Y Li, X Li, L Xu, Y Liu, H Zhao, D Liu, J Hu; (IV) Collection and assembly of data: X Peng; (V) Data analysis and interpretation: J Xu, H Ni, Y \\ Wu, J Cao; (VI) Manuscript writing: All authors; (VII) Final approval of manuscript: All authors. \\ Correspondence to: Jian Hu. Department of Thoracic Surgery, the First Affiliated Hospital, Zhejiang University School of Medicine, No. 79 Qing- \\ chun Road, Hangzhou, China. Email: dr_hujian@zju.edu.cn.
}

Background: Compared with open surgery, video-assisted thoracic surgery (VATS) has innovated the concept of the minimally invasive approach for non-small cell lung cancer (NSCLC) patients in past decades. This present study aimed to compare the perioperative and lymph node dissection outcomes between VATS lobectomy and open lobectomy for pathological stage T1 (pT1) NSCLC patients from both surgical and oncologic perspectives.

Methods: This was a retrospective multicenter study. Patients who underwent surgical resection for pT1 NSCLC between January 2014 and September 2017 were retrospectively reviewed from 10 thoracic surgery centers in China. Perioperative and lymph node dissection outcomes of pT1 NSCLC patients who accepted VATS or open lobectomies were compared by propensity score matching (PSM) analysis.

Results: Of the 11,360 patients who underwent surgery for pT1 NSCLC, 7,726 were enrolled based on the selection criteria, including 1,222 cases of open lobectomies and 6,504 cases of VATS lobectomies. PSM resulted in 1,184 cases of open lobectomies and 1,184 cases of VATS lobectomies being well matched by common prognostic variables, including age, sex, and surgical side. VATS lobectomy led to better perioperative outcomes, including less blood loss $(133.5 \pm 200.1$ vs. $233.3 \pm 318.4, \mathrm{P}<0.001)$, lower blood transfusion rate $(2.4 \%$ vs. $6.4 \%, \mathrm{P}<0.001)$, shorter postoperative hospital stay $(8.6 \pm 5.7$ vs. $10.1 \pm 5.1, \mathrm{P}<0.001)$, less chest drainage volume $(1,109.5 \pm 854.0$ vs. $1,324.1 \pm 948.8, \mathrm{P}<0.001)$, and less postoperative complications (4.9\% vs. 8.2\%, $\mathrm{P}<0.001$ ). However, open lobectomy had better lymph node dissection outcomes than VATS, with increased lymph node dissection numbers $(16.1 \pm 9.4$ vs. $13.7 \pm 7.7, \mathrm{P}<0.001)$ and more positive lymph nodes being dissected $(1.5 \pm 3.9$ vs. $1.1 \pm 2.5, \mathrm{P}=0.002)$. Compared with VATS, open lobectomy harvested more lymph node stations $(5.5 \pm 1.9$ vs. $5.2 \pm 1.8, \mathrm{P}=0.001$ ), including more pathological $\mathrm{N} 2$ (pN2) lymph node stations $(3.4 \pm 1.4$ vs. $3.1 \pm 1.3, \mathrm{P}<0.001)$.

Conclusions: VATS lobectomy was associated with better perioperative outcomes, such as less blood loss, lower blood transfusion rate, shorter postoperative hospital stay, less chest drainage volume and less postoperative complications. Open lobectomy has improved lymph node dissection outcomes, as more lymph 
nodes and positive lymph nodes were dissected for pT1 NSCLC patients during surgery.

Keywords: Non-small cell lung cancer (NSCLC); pathological stage T1; thoracic surgery; video-assisted thoracic surgery (VATS); perioperative outcomes; lymph node dissection

Submitted Sep 24, 2020. Accepted for publication Nov 24, 2020.

doi: $10.21037 /$ tlcr-20-1132

View this article at: http://dx.doi.org/10.21037/tlcr-20-1132

\section{Introduction}

Lung cancer is the most frequent cause of cancer-related death worldwide $(1,2)$. It is estimated that there were approximately 774,323 new cases and 690,567 cancerrelated deaths in China in 2018 (3). Approximately 85\% of all lung cancers are non-small cell lung cancer (NSCLC) (4). Despite decades of efforts, the 5-year survival of patients with lung cancer is still limited to $4-17 \%$, depending on the stage and reginal differences (5). Open thoracotomy incision was the predominant approach for lung cancer surgery for decades, and video-assisted thoracic surgery (VATS) emerged as a minimally invasive alternative approach for lung cancer surgery in the early 1990s (6). VATS has been defined as the individual transection of lobar bronchus and vessels via the guidance of video screening through ports in the chest wall without rib spreading (7). Because of the minimal invasion associated with VATS its use in treating early-stage NSCLC has increased over years (8-12), and studies have demonstrated the advantages of VATS compared with open thoracotomy, including a lower morbidity rate $(8,13-15)$, shorter chest tube duration $(13,14)$, less intraoperative blood loss (14), and shorter postoperative hospital stay $(8,13-17)$. However, the surgical skills of VATS need practice and training and there is potential risk of uncontrollable bleeding by VATS (18-22).

Despite the advantages associated with short-term outcomes, the oncologic efficacy has been questioned, with some studies reporting that VATS is less or equally efficient in nodal upstaging when compared with open lobectomy (11,12,23-25). However, most studies focused on stage I or II patients $(26,27)$, and the lymph node dissection extent, metastasis rate and pathological stage might be affected by the surgical approach. Therefore, it is important to investigate the role of surgical approach in lymph node staging in small-size lung cancer. Of note, however, is that, to the best of our knowledge, no study has comprehensively compared the lymph node dissection outcomes between VATS and open lobectomy in pT1 patients.

The main purpose of this study was to compare the lymph node dissection outcomes as long as perioperative outcomes between VATS and open thoracotomy lobectomy for pathological stage T1 (pT1) NSCLC patients from 10 thoracic surgery centers in China. We present the following article in accordance with the STROBE reporting checklist (available at http://dx.doi.org/10.21037/tlcr-20-1132).

\section{Methods}

\section{Data source}

The present study was a multicenter retrospective cohort study of patients with surgically resected pT1 lung cancer who underwent surgery for NSCLC between January 2014 and September 2017. The clinical and pathological information of patients was collected and sorted with the assistance of the Large-scale Data Analysis Center of Cancer Precision Medicine-LinkDoc database $(28,29)$. The study was conducted in accordance with the Declaration of Helsinki (as revised in 2013).

\section{Patient selection}

A total of 11,360 patients with surgically resected lung cancer were identified from the database, and 7,726 patients were finally included. The inclusion criteria were as follows: patients who underwent VATS or open lobectomy, and patients with stage pT1 NSCLC. The exclusion criteria were as follows: surgical approach other than VATS and the open approach (robotic or other approaches), cancer other than NSCLC, and surgery other than lobectomy. The patient selection flowchart is shown in Figure 1. The present study was approved by the ethical review board of each participating center. Informed consent was waived for this retrospective study. 


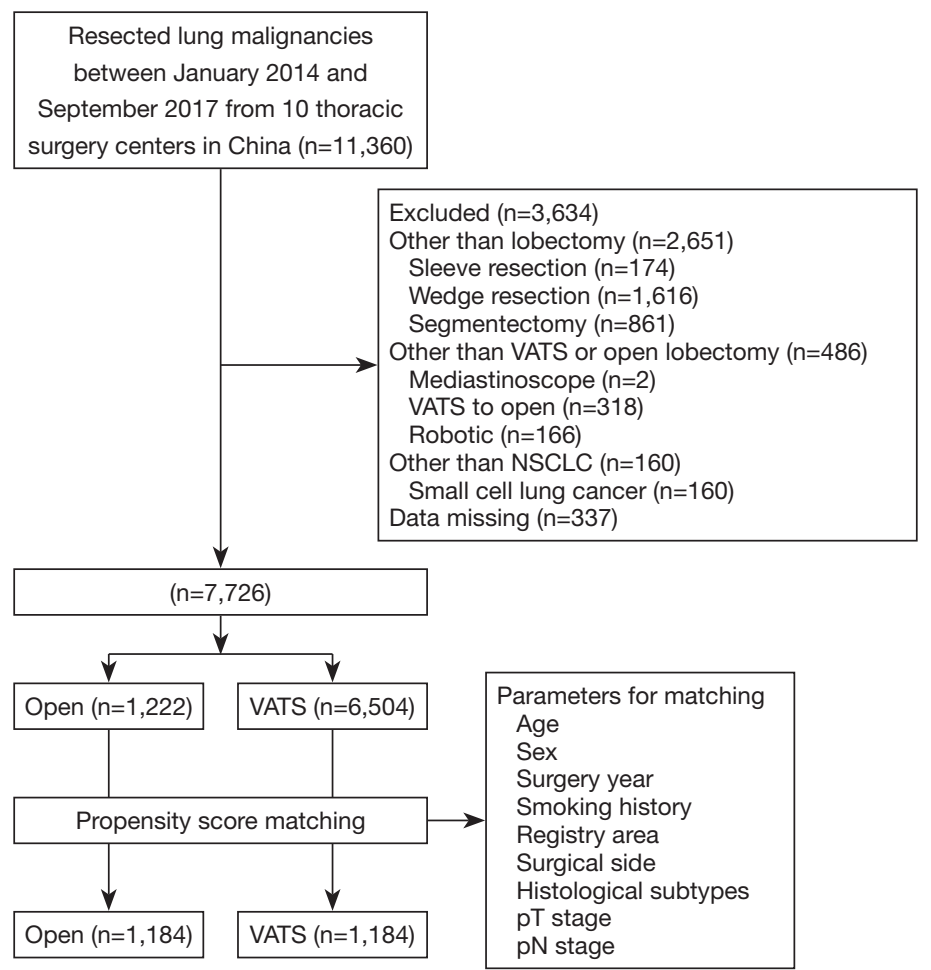

Figure 1 Patients inclusion criteria. NSCLC, non-small cell lung cancer; pN stage, pathological N stage; pT stage, pathological T stage; VATS, video-assisted thoracic surgery.

\section{Data evaluation}

Clinical and pathological information were retrospectively collected from 10 thoracic surgery centers. Baseline and clinical characteristics included age, sex, surgery year, registry area, surgical side, tumor size, smoking history, histological subtypes, pT stage, and pathological $\mathrm{N}$ (pN) stage. Outcome assessment variables included intraoperative blood loss and transfusion rate, postoperative hospital stay, duration of chest drainage and drainage volume, operation duration, surgical margin, and postoperative complications. Lymph node evaluation was performed, which included the number of lymph nodes dissected, number of positive lymph nodes dissected, station number of lymph nodes dissected, and station number of positive lymph nodes dissected. All information was retrospectively reviewed and analyzed to compare the postoperative and lymph node dissection outcomes between VATS and open lobectomy.

\section{Statistical analysis}

Continuous variables were expressed as mean \pm standard deviation (SD), and were analyzed by Student's $t$-test and rank sum test. Categorical variables were expressed as frequencies and percentages and were analyzed by $\chi^{2}-$ test. Propensity score matching (PSM) was performed to eliminate selection bias and balance the baseline characteristics between two groups by using the nearest matching method with a 1:1 ratio. The caliper width for PSM was chosen as 0.2 times that of the SD of the logit of the propensity score (30). The variables involved in the PSM were age, sex, surgery year, registry area, surgical side, smoking history, histological subtypes, pT stage, and $\mathrm{pN}$ stage. Statistical analysis was performed using SPSS for Windows, version 26.0 (SPSS IBM, Armonk, NY, USA). All statistical tests were 2 sided, and $\mathrm{P}<0.05$ was considered statistically significant.

\section{Results}

A total of 21,790 patients who underwent thoracic surgery between January 2014 and September 2017 from 10 thoracic centers in China were identified; 7,726 patients, including 6,504 cases of VATS and 1,222 cases of open 
lobectomy, were enrolled in the study according to the inclusion criteria. The percentage of pT1 NSCLC patients who underwent VATS was $84.2 \%$, which was higher than that of previously reported studies $(7,24,25)$.

\section{Complete cohort}

The detailed baseline clinical characteristics are listed in Table 1. Patients who underwent VATS were younger than those who underwent open lobectomy $(59.0 \pm 9.5 \mathrm{vs}$. $61.1 \pm 8.6, \mathrm{P}<0.001)$. There were more female patients and patients from Southern China, and fewer current or former smokers in the VATS group compared with the open lobectomy group. There were also more patients diagnosed with adenocarcinoma in the VATS group compared with the open lobectomy group $(91.3 \%$ vs. $71.6 \%, \mathrm{P}<0.001)$, and patients in the VATS group had smaller tumor sizes compared with the lobectomy open group $(1.8 \pm 0.7 \mathrm{vs}$. $2.1 \pm 0.7, \mathrm{P}<0.001$ ).

The assessment outcomes are listed in Table 2. Patients who underwent VATS had less blood loss $(113.1 \pm 171.2$ vs. 235.0 $\pm 318.2, \mathrm{P}<0.001)$ and a lower blood transfusion rate $(1.7 \%$ vs. $6.5 \%, \mathrm{P}<0.001)$ compared with the open lobectomy group. Patients who underwent VATS had a shorter average duration of hospital stay $(8.0 \pm 5.3 \mathrm{vs}$. $10.16 \pm 5.2, \mathrm{P}<0.001)$, chest tube $(5.1 \pm 4.4$ vs. $6.3 \pm 5.3$, $\mathrm{P}<0.001)$, and operation $(146.1 \pm 59.5$ vs. $159.8 \pm 66.4$, $\mathrm{P}<0.001)$ compared with the open lobectomy group. The negative surgical margin rate was higher $(98.9 \%$ vs. $96.5 \%$, $\mathrm{P}<0.001$ ), and the postoperative complication rate was lower in the VATS group compared with the open lobectomy group (93.9\% vs. $92.0 \%, \mathrm{P}=0.014)$.

Open lobectomy was found to be more superior for lymph node dissection, as it outnumbered VATS in total lymph nodes dissected $(16.2 \pm 9.4$ vs. $12.5 \pm 7.3, \mathrm{P}<0.001)$, $\mathrm{pN} 1$ lymph nodes dissected $(6.4 \pm 4.5$ vs. $5.4 \pm 4.0, \mathrm{P}<0.001)$, and $\mathrm{pN} 2$ lymph nodes dissected $(9.7 \pm 6.8$ vs. $7.2 \pm 5.3$, $\mathrm{P}<0.001)$. Open lobectomy was also superior compared with VATS in terms of positive lymph nodes dissected $(1.6 \pm 4.0$ vs. $0.5 \pm 1.8, \mathrm{P}<0.001)$ and station number of positive lymph nodes dissected $(0.8 \pm 1.4$ vs. $0.3 \pm 0.9, \mathrm{P}<0.001)$. Regarding the station number of lymph nodes dissected, however, open lobectomy only exhibited advantages in total station number of lymph nodes dissected $(5.5 \pm 1.8$ vs. $5.2 \pm 1.7$, $\mathrm{P}<0.001)$ and $\mathrm{pN} 2$ station number of lymph nodes dissected ( $3.5 \pm 1.3$ vs. $3.2 \pm 1.1, \mathrm{P}<0.001)$, but no significant difference was found in $\mathrm{pN} 1$ station number of lymph nodes dissected (2.2 \pm 0.8 vs. $2.2 \pm 0.9, \mathrm{P}=0.444)$.

\section{Matched cobort}

Following PSM, 1,184 cases of VATS and 1,184 cases of open lobectomy were identified based on the common prognostic variables mentioned earlier. The detailed baseline clinical characteristics of the matched cohort are listed in Table 3. In the matched population, variables, including age, surgery year, sex, registry area, surgical side, smoking history, histology, tumor size, pT stage, and $\mathrm{pN}$ stage, were comparable between the two groups. Perioperative outcomes and lymph node involvement are summarized in Table 4. After matching, patients who underwent VATS still had less blood loss $(133.5 \pm 200.1$ vs. $233.3 \pm 318.4, \mathrm{P}<0.001)$ and a lower blood transfusion rate $(2.4 \%$ vs. $6.4 \%, \mathrm{P}<0.001)$ than patients in the open lobectomy group. Shorter postoperative hospital stay $(8.6 \pm 5.7$ vs. $10.1 \pm 5.1, \mathrm{P}<0.001)$ and lower chest drainage volume $(1,109.5 \pm 854.0$ vs. $1,324.1 \pm 948.8, \mathrm{P}<0.001)$ were also observed in the VATS group compared with the open lobectomy group. However, in the matched cohort, no significant difference was found in the duration of chest tube $(5.8 \pm 5.4 v s .6 .1 \pm 5.1, \mathrm{P}=0.190)$ and operation $(154.2 \pm 60.9$ vs. $158.9 \pm 66.4, \mathrm{P}=0.080)$ between VATS and open lobectomy. Patients who underwent VATS exhibited a higher negative surgical margin $98.7 \%$ vs. $97.4 \%, \mathrm{P}=0.017$ ) and lower postoperative complications rate $(4.9 \%$ vs. $8.2 \%$, $\mathrm{P}=0.001)$ compared with the open lobectomy group.

Regarding lymph node involvement, open lobectomy was superior in terms of lymph node dissection, as it outnumbered VATS in total lymph nodes dissected $(16.1 \pm 9.4$ vs. $13.7 \pm 7.7, \mathrm{P}<0.001)$, $\mathrm{pN} 1$ lymph nodes dissected $(6.4 \pm 4.4$ vs. $5.8 \pm 3.9, \mathrm{P}<0.001)$, and $\mathrm{pN} 2$ lymph nodes dissected (9.6 \pm 6.8 vs. $7.9 \pm 5.9, \mathrm{P}<0.001)$. Open lobectomy was also superior in terms of positive lymph nodes dissected $(1.5 \pm 3.9$ vs. $1.1 \pm 2.5, \mathrm{P}=0.002)$, but not in terms of the station number of positive lymph nodes dissected $(0.7 \pm 1.4$ vs. $0.7 \pm 1.2$, $\mathrm{P}=0.225$ ). Consistent with the results in the complete cohort, open lobectomy only exhibited advantages in total station number of lymph nodes dissected $(5.5 \pm 1.9$ vs. $5.2 \pm 1.8, \mathrm{P}=0.001)$ and $\mathrm{pN} 2$ station number of lymph nodes dissected $(3.4 \pm 1.4$ vs. $3.1 \pm 1.3, \mathrm{P}<0.001)$, but no significant difference was found between VATS and open lobectomy in $\mathrm{pN} 1$ station number of lymph nodes dissected $(2.1 \pm 0.9 \mathrm{vs}$. $2.1 \pm 1.0, \mathrm{P}=0.931)$.

\section{Subgroup analysis}

To obtain a better understanding of lymph node dissection 
Table 1 Baseline characteristics of pathological T1 NSCLC patients

\begin{tabular}{|c|c|c|c|}
\hline Patient characteristics & Open lobectomy $(n=1,222)$ & VATS $(n=6,504)$ & $P$ value \\
\hline$\leq 55$ & $295(24.1)$ & $2,193(33.7)$ & $<0.001$ \\
\hline $55-65$ & $523(42.8)$ & 2,482 (38.2) & \\
\hline$\geq 65$ & $404(33.1)$ & $1,829(28.1)$ & \\
\hline Male & $751(61.5)$ & $2,995(46.0)$ & \\
\hline Female & $471(38.5)$ & $3,509(54.0)$ & \\
\hline Surgery year, n (\%) & & & $<0.001$ \\
\hline 2014 & $35(2.9)$ & $132(2.0)$ & \\
\hline 2017 & $315(25.8)$ & $2,093(32.2)$ & \\
\hline Smoking history, n (\%) & & & $<0.001$ \\
\hline Current or former smokers & $526(43.0)$ & $1,873(28.8)$ & \\
\hline Non-smokers & $696(57.0)$ & 4,631 (71.2) & \\
\hline Registry area, n (\%) & & & $<0.001$ \\
\hline South & $611(50.0)$ & $3,794(58.3)$ & \\
\hline North & $611(50.0)$ & $2,710(41.7)$ & \\
\hline Surgical side, $\mathrm{n}(\%)$ & & & $<0.001$ \\
\hline Squamous carcinoma & $347(28.4)$ & $568(8.7)$ & \\
\hline Pathological T stage, n (\%) & & & $<0.001$ \\
\hline $\mathrm{T} 1 \mathrm{a}$ & $152(12.4)$ & $1,483(22.8)$ & \\
\hline $\mathrm{T} 1 \mathrm{~b}$ & $489(40.0)$ & $3,061(47.1)$ & \\
\hline $\mathrm{T} 1 \mathrm{c}$ & $581(47.5)$ & $1,960(30.1)$ & \\
\hline \multicolumn{4}{|l|}{ Pathological N stage, n (\%) } \\
\hline No & $821(67.2)$ & $5,545(85.2)$ & $<0.001$ \\
\hline $\mathrm{N} 1$ & $135(11.0)$ & $347(5.3)$ & \\
\hline N2 & 260 (21.3) & 609 (9.4) & \\
\hline N3 & $6(0.5)$ & $3(0.05)$ & \\
\hline
\end{tabular}

NSCLC, non-small cell lung cancer; SD, standard deviation; VATS, video-assisted thoracic surgery. 
Table 2 Perioperative outcomes and lymph node involvement between VATS and open lobectomy

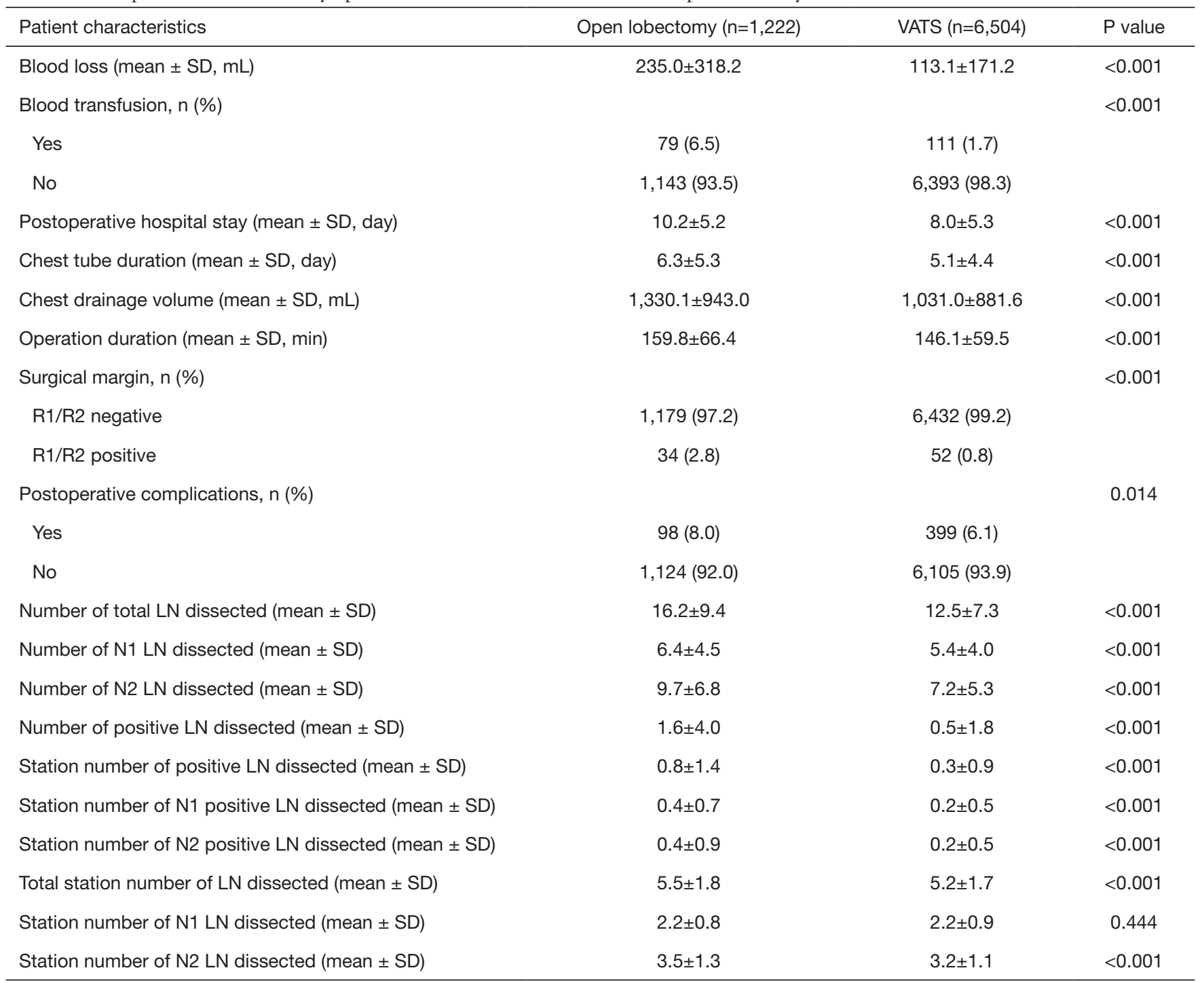

LN, lymph nodes; SD, standard deviation; VATS, video-assisted thoracic surgery.

outcomes between VATS and open lobectomy in earlystage NSCLC patients, we further split the matched cohort into three subgroups based on pT1 categories. As shown in Table 5, there was a significant difference between VATS and open lobectomy in $\mathrm{pN}$ stage patients with tumor size $<1 \mathrm{~cm}(\mathrm{P}=0.002)$. More lymph nodes and $\mathrm{pN} 2$ lymph nodes could be harvested in open lobectomy compared with VATS in all three pT1 categories, but there was no significant difference in pN1 lymph nodes dissected in pT1a and pT1c NSCLC patients. In pT1b NSCLC patients, the positive lymph node dissection numbers between open lobectomy and VATS were comparable $(1.3 \pm 4.0$ vs. $1.0 \pm 2.4, \mathrm{P}=0.105)$.
Regarding the station number of lymph nodes dissected, the two surgical approaches showed no significant difference, but more lymph node stations, as well as $\mathrm{pN} 2$ lymph node stations, could be harvested in open lobectomy in pT1a and pT1c NSCLC patients compared with VATS.

\section{Discussion}

The present study was performed based on the Largescale Data Analysis Center of Cancer Precision MedicineLinkDoc database, which collected the clinical and pathological information of lung cancer patients who 
Table 3 Baseline characteristics of pathological T1 NSCLC patients after propensity score matching

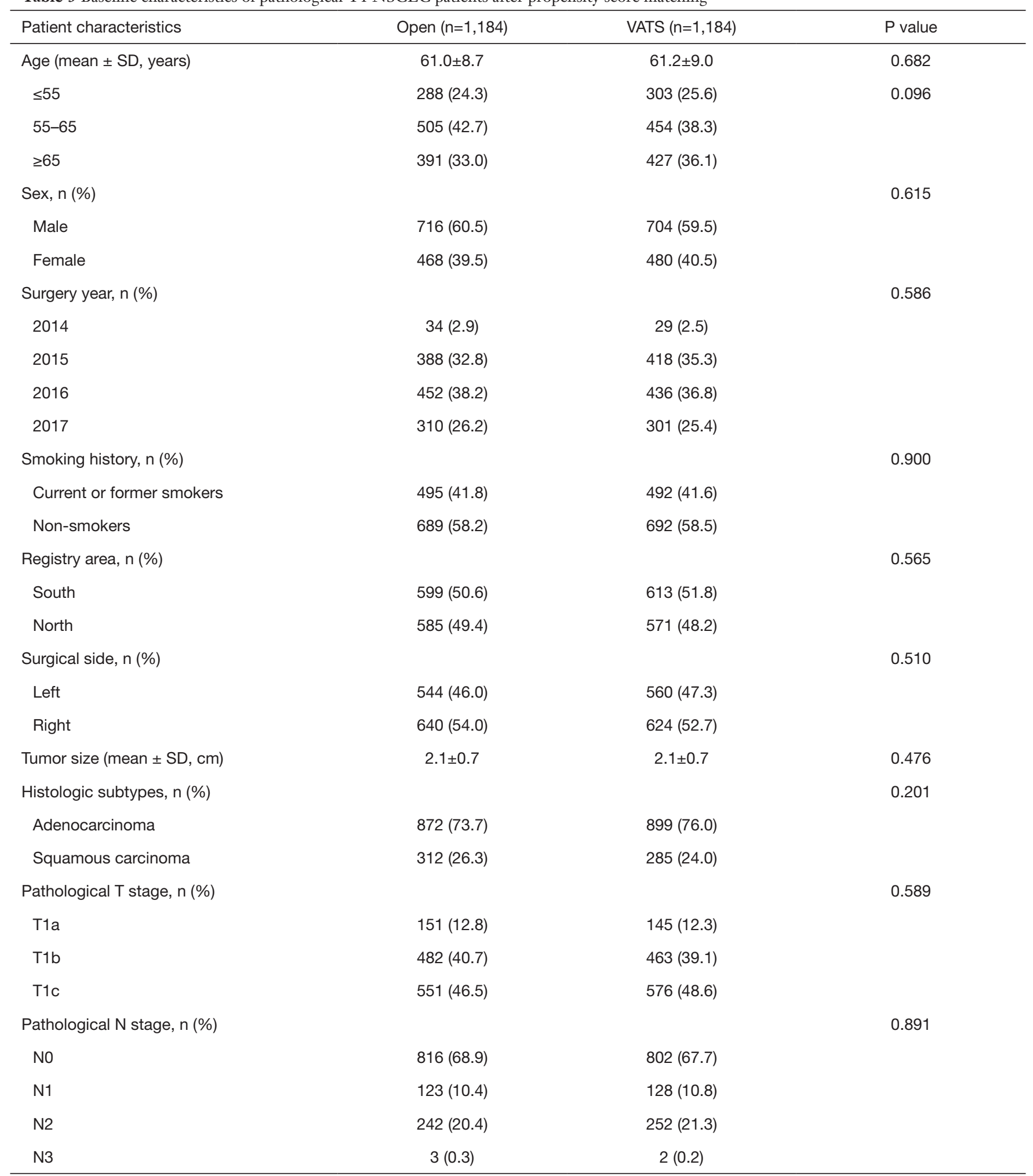

NSCLC, non-small cell lung cancer; SD, standard deviation; VATS, video-assisted thoracic surgery. 
Table 4 Perioperative outcomes and LN involvement between VATS and open lobectomy after propensity score matching

\begin{tabular}{|c|c|c|c|}
\hline Patient characteristics & Open lobectomy $(n=1,184)$ & VATS $(n=1,184)$ & $P$ value \\
\hline Blood transfusion, $\mathrm{n}(\%)$ & & & $<0.001$ \\
\hline Yes & $76(6.4)$ & $29(2.4)$ & \\
\hline No & $1,108(93.6)$ & $1,155(97.6)$ & \\
\hline Chest tube duration (mean $\pm \mathrm{SD}$, day) & $6.1 \pm 5.1$ & $5.8 \pm 5.4$ & 0.190 \\
\hline Chest drainage volume (mean $\pm \mathrm{SD}, \mathrm{mL}$ ) & $1,324.1 \pm 948.8$ & $1,109.5 \pm 854.0$ & $<0.001$ \\
\hline Operation duration (mean $\pm \mathrm{SD}$, min) & $159.4 \pm 66.9$ & $158.7 \pm 63.7$ & 0.783 \\
\hline Surgical margin, n (\%) & & & 0.017 \\
\hline Postoperative complications, n (\%) & & & 0.001 \\
\hline Yes & $97(8.2)$ & $58(4.9)$ & \\
\hline No & $1,087(91.8)$ & $1,126(95.1)$ & \\
\hline Number of total LN dissected (mean $\pm \mathrm{SD}$ ) & $16.1 \pm 9.4$ & $13.7 \pm 7.7$ & $<0.001$ \\
\hline Number of N1 LN dissected (mean \pm SD) & $6.4 \pm 4.4$ & $5.8 \pm 3.9$ & $<0.001$ \\
\hline Number of N2 LN dissected (mean \pm SD) & $9.6 \pm 6.8$ & $7.9 \pm 5.9$ & $<0.001$ \\
\hline Number of positive LN dissected (mean \pm SD) & $1.5 \pm 3.9$ & $1.1 \pm 2.5$ & 0.002 \\
\hline Station number of positive LN dissected (mean \pm SD) & $0.7 \pm 1.4$ & $0.7 \pm 1.2$ & 0.225 \\
\hline
\end{tabular}

LN, lymph nodes; SD, standard deviation; VATS, video-assisted thoracic surgery.

underwent surgery from 10 thoracic centers in China. The perioperative and lymph node dissection outcomes of $\mathrm{pT} 1$ NSCLC patients who underwent VATS or open lobectomy from January 2014 to September 2017 were compared. Of note, the proportion of VATS increased annually during the study period, which resulted in significantly more VATS patients enrolled in the present study compared to open lobectomy patients $(6,504$ vs. 1,222). Therefore, PSM was implemented to eliminate the selection bias and balance the intrinsic difference.

In the present study, we confirmed that VATS was associated with better perioperative outcomes, which is consistent with many previously published studies $(8,9,31)$. Briefly, compared with the open lobectomy group, patients who underwent VATS had less intraoperative blood loss, as well as a lower blood transfusion rate. The average time of postoperative hospital stay was also found to be shorter in VATS compared with open lobectomy. Patients who underwent VATS had lower postoperative complications rate than those who underwent open lobectomy. However, in our study, patients who underwent open lobectomy had better lymph node dissection outcomes. More lymph nodes, more positive lymph nodes, and more lymph node stations were harvested in open lobectomy. 


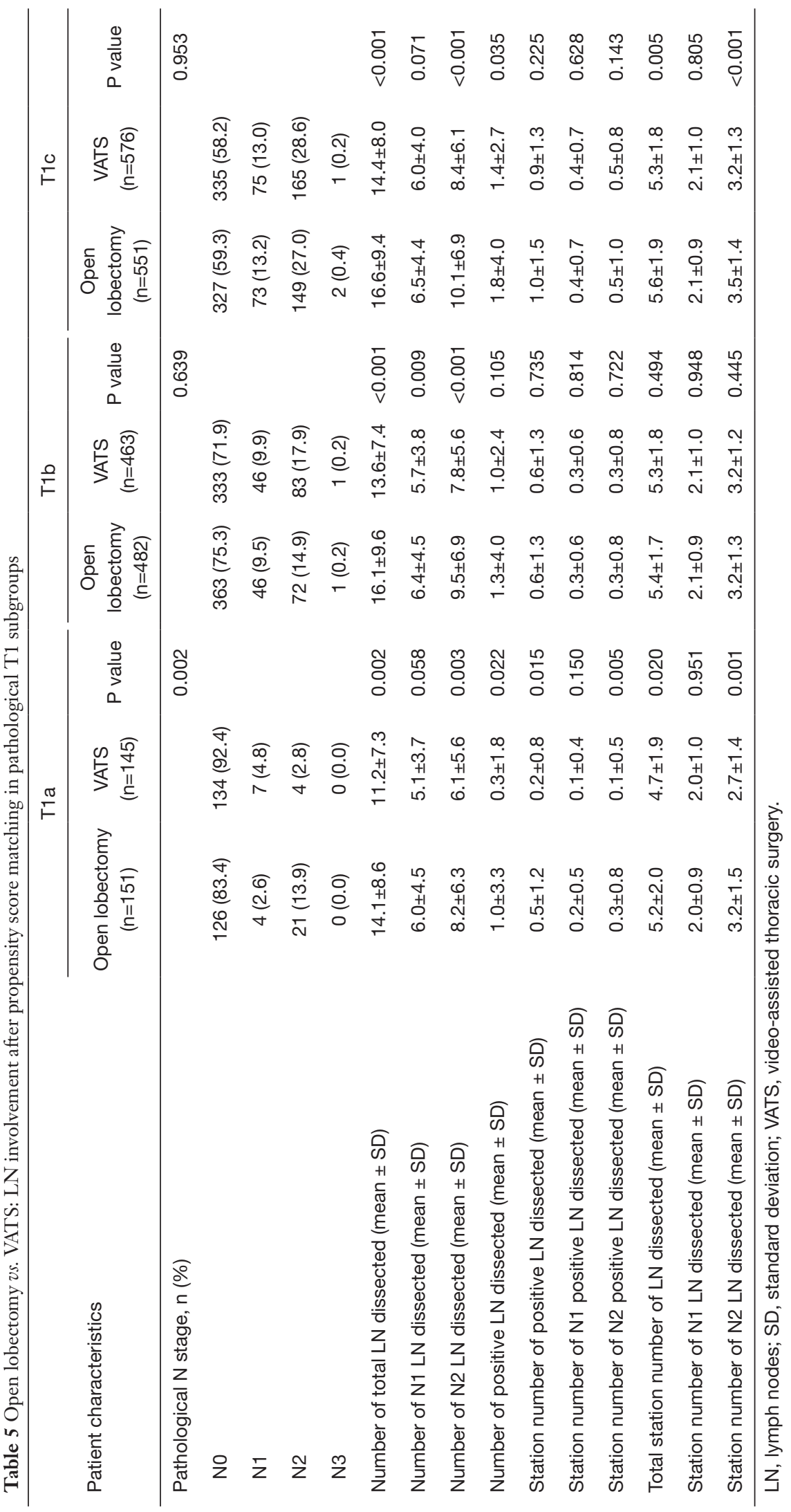


Better perioperative outcomes have long been found in patients who underwent VATS compared with open lobectomy. In the present study, VATS suggested less blood loss, lower blood transfusion rate, shorter postoperative hospital stay, less chest drainage volume and less postoperative complications. Due to the minimally invasive incision of VATS, intraoperative bleeding was reduced $(7,14,32,33)$ and intraoperative blood transfusion rate decreased accordingly (13). The process of enhanced recovery after surgery has also been improved by minimal invasive approach (34). Shorter postoperative hospital stay for VATS approach was confirmed in most of the unmatched or matched comparisons $(7,8,14,33,35,36)$. Besides, patients who underwent VATS were confirmed to have fewer postoperative complications in many previous studies $(7,8,13,14,31,37-40)$, such as pneumonia $(7,14,38,39)$, empyema (13), atelectasis $(31,38,40)$ and arrhythmia (38). However, the incidence of postoperative complications after VATS varies between studies, from $<10 \%$ to as high as $40.8 \%$ and $45.1 \%$ for open lobectomy. In our cohort, the postoperative complication rate was much lower than that in the aforementioned reports. The incidence variance between different studies might largely be due to the technical level in different hospital and in different countries. Also, a lack of universal criteria for the definition of postoperative complications could contribute to the incidence variance between studies. What's more, it has been also reported that compared with open surgery, VATS had lower incidence of pain and improved quality of life (41). However, in terms of chest tube duration and chest drainage volume, there have been controversies $(7,13,32)$. In the present multi-center propensity score matching study, we found that VATS had less chest drainage volume but not significant results of chest tube duration compared with open surgery. More well-designed prospective research should be carried out to investigate this issue.

As well as perioperative outcomes, we found that open lobectomy had better lymph node dissection outcomes compared with VATS. Concerns about its efficiency in lymph node dissection have long been proposed since the introduction of VATS in the 1990s. The outcomes of lymph node dissection between VATS and open lobectomy are still controversial, and the lack of consensus on how to systematically evaluate lymph node dissection outcomes, such as the number of dissected lymph nodes or upstaging rate, further complicates this situation $(17,23,25,35,42)$. Boffa et al. evaluated lymph node involvement outcomes between VATS and open surgery in 11,500 stage I lung cancer patients who underwent anatomical resection; a higher upstaging rate for $\mathrm{N} 0$ and $\mathrm{N} 1$ patients in the open group was found $(9.3 \%$ vs. $6.7 \%, \mathrm{P}<0.001)(43)$. A similar PSM study by Medbery et al. in 2016 also found that, compared with VATS, open lobectomy had a higher upstaging rate $(12.8 \%$ vs. $10.3 \%, \mathrm{P}<0.001)(23)$. However, results from different studies have indicated that there is no such difference between these two approaches. In a national analysis of long-term survival between VATS and open lobectomy, Yang et al. reported that there was no significant difference in the upstaging rate between the two approaches (11.2\% vs. $12.5 \%, \mathrm{P}=0.46$ ) (17). As well as the upstaging rate, the number of lymph nodes dissected was also a major concern of lymph node assessment. In a PSM study, Zhang et al. reported that more group 7 mediastinal lymph nodes were harvested with open lobectomy compared with VATS [8.78 (8.04-9.41) vs. 7.52 (6.76-7.94), $\mathrm{P}<0.01]$ (35). Regarding total lymph node dissection number, Merritt et al. found that more lymph nodes were harvested with open lobectomy compared with VATS $(14.7 \pm 1.3 v s .9 .9 \pm 0.8$, $\mathrm{P}=0.003$ ) (44). In contrast, Mei et al. found that, compared with open lobectomy, more lymph node stations were removed with VATS $(4.9 \pm 1.5$ vs. $4.2 \pm 1.8, \mathrm{P}<0.001)(7)$. However, to the best of our knowledge, there has been no study that has systematically compared lymph node dissection outcomes between VATS and open lobectomy in pT1 NSCLC patients. In this present multicenter retrospective study, we found that, compared with VATS, open lobectomy was superior in total lymph nodes dissected $(16.1 \pm 9.4$ vs. $13.7 \pm 7.7, \mathrm{P}<0.001)$. Open lobectomy was also superior to VATS in terms of positive lymph nodes dissected $(1.5 \pm 3.9$ vs. $1.1 \pm 2.5, \mathrm{P}=0.002)$ and station number of lymph nodes dissected $(5.5 \pm 1.9$ vs. $5.2 \pm 1.8, \mathrm{P}=0.001)$. In the present study, we compared the perioperative and lymph node dissection outcomes between VATS lobectomy and open thoracotomy for pT1 NSCLC patients from both surgical and oncologic perspectives. In past decades, more early-stage NSCLC has been detected and VATS has been widely used in thoracic surgery because of its advantage in enhanced recovery after surgery (45). More attention should be paid to the differences in lymph node dissection caused by changes in surgical methods for early lung cancer. As we found in the present study, more lymph nodes could be harvested with open lobectomy compared with VATS, which might lead to more positive lymph nodes and more lymph node stations being dissected. In the subgroup analysis, compared with other groups, T1a patients who underwent open lobectomy had significantly 
higher $\mathrm{pN}$ stage than those underwent VATS, with a $\mathrm{pN} 2$ rate of $13.9 \%$. Patients with relatively small tumor size were usually considered to have little possibility of developing metastatic lymph nodes. However, the results of our study suggest that the lower efficiency of VATS for the dissection of positive lymph node stations, especially $\mathrm{pN} 2$ positive lymph node stations $(0.1 \pm 0.5$ vs. $0.3 \pm 0.8, \mathrm{P}=0.005)$ for $\mathrm{T} 1 \mathrm{a}$ patients, might contribute to this misconception. Therefore, systematic lymph node dissection, critical lymph node staging, and optimal surgery warrant further attention, even for early pT1 NSCLC.

The present study has some limitations. First, due to the short follow-up time, the 5-year overall survival information was lacking, and we hope to further report the survival data in future. Second, the intrinsic limitation of retrospective might cause unobserved confounding and selection bias between the two approaches, even though PSM had been adopted to eliminate such bias.

In conclusion, for patients who have pT1 NSCLC, VATS lobectomy has better perioperative outcomes, such as less blood loss, lower blood transfusion rate, shorter postoperative hospital stay, less chest drainage volume and less postoperative complications, compared with open lobectomy. However, open lobectomy is superior to VATS in terms of lymph node dissection, including total number of lymph node, dissected, station number of lymph node dissected, and number of positive lymph nodes dissected. Thoracic surgeons should pay more attention to VATS lymph node dissection for $\mathrm{pT} 1$ patients.

\section{Acknowledgments}

Funding: The present study was funded by the National Key R\&D Program of China (No. 2017YFC0113500), Major Science and Technology Projects of Zhejiang Province (2020C03058), Diagnosis and Treatment Technology Research Center of Pulmonary Neoplasm in Zhejiang Province (JBZX-202007), and Key Disciplines of Traditional Chinese Medicine in Zhejiang Province (No. 2017-XK-A33). The funders had no role in the study design, data collection and analysis, decision to publish, or preparation of the manuscript.

\section{Footnote}

Reporting Checklist: The authors have completed the STROBE reporting checklist. Available at http://dx.doi. org/10.21037/tlcr-20-1132
Conflicts of Interest: All authors have completed the ICMJE uniform disclosure form (available at http://dx.doi. org/10.21037/tlcr-20-1132). The authors have no conflicts of interest to declare.

Ethical Statement: The authors are accountable for all aspects of the work in ensuring that questions related to the accuracy or integrity of any part of the work are appropriately investigated and resolved. The study was conducted in accordance with the Declaration of Helsinki (as revised in 2013).

Open Access Statement: This is an Open Access article distributed in accordance with the Creative Commons Attribution-NonCommercial-NoDerivs 4.0 International License (CC BY-NC-ND 4.0), which permits the noncommercial replication and distribution of the article with the strict proviso that no changes or edits are made and the original work is properly cited (including links to both the formal publication through the relevant DOI and the license). See: https://creativecommons.org/licenses/by-nc-nd/4.0/.

\section{References}

1. Siegel RL, Miller KD, Jemal A. Cancer statistics, 2015. CA Cancer J Clin 2015;65:5-29.

2. Torre LA, Bray F, Siegel RL, et al. Global cancer statistics, 2012. CA Cancer J Clin 2015;65:87-108.

3. Feng RM, Zong YN, Cao SM, et al. Current cancer situation in China: good or bad news from the 2018 Global Cancer Statistics? Cancer Commun (Lond) 2019;39:22.

4. Zhang YK, Chai ZD, Tan LL, et al. Association of lymph node involvement with the prognosis of pathological T1 invasive non-small cell lung cancer. World J Surg Oncol 2017;15:64.

5. Hirsch FR, Scagliotti GV, Mulshine JL, et al. Lung cancer: current therapies and new targeted treatments. Lancet 2017;389:299-311.

6. Sihoe ADL. Video-assisted thoracoscopic surgery as the gold standard for lung cancer surgery. Respirology 2020;25 Suppl 2:49-60.

7. Mei J, Guo C, Xia L, et al. Long-term survival outcomes of video-assisted thoracic surgery lobectomy for stage I-II non-small cell lung cancer are more favorable than thoracotomy: a propensity score-matched analysis from a high-volume center in China. Transl Lung Cancer Res 2019;8:155-66.

8. Nwogu CE, D'Cunha J, Pang H, et al. VATS lobectomy 
has better perioperative outcomes than open lobectomy: CALGB 31001, an ancillary analysis of CALGB 140202 (Alliance). Ann Thorac Surg 2015;99:399-405.

9. Mun M, Nakao M, Matsuura Y, et al. Video-assisted thoracoscopic surgery lobectomy for non-small cell lung cancer. Gen Thorac Cardiovasc Surg 2018;66:626-31.

10. Howington JA, Blum MG, Chang AC, et al. Treatment of stage I and II non-small cell lung cancer: Diagnosis and management of lung cancer, 3rd ed: American College of Chest Physicians evidence-based clinical practice guidelines. Chest 2013;143:e278S-e313S.

11. Ettinger DS, Wood DE, Aggarwal C, et al. NCCN Guidelines Insights: Non-Small Cell Lung Cancer, Version 1.2020. J Natl Compr Canc Netw 2019;17:1464-72.

12. Postmus PE, Kerr KM, Oudkerk M, et al. Early and locally advanced non-small-cell lung cancer (NSCLC): ESMO Clinical Practice Guidelines for diagnosis, treatment and follow-up. Ann Oncol 2017;28:iv1-iv21.

13. Paul S, Altorki NK, Sheng S, et al. Thoracoscopic lobectomy is associated with lower morbidity than open lobectomy: a propensity-matched analysis from the STS database. J Thorac Cardiovasc Surg 2010;139:366-78.

14. Chen FF, Zhang D, Wang YL, et al. Video-assisted thoracoscopic surgery lobectomy versus open lobectomy in patients with clinical stage non-small cell lung cancer: a meta-analysis. Eur J Surg Oncol 2013;39:957-63.

15. Hernandez-Vaquero D, Vigil-Escalera C, Pérez-Méndez I, et al. Survival after thoracoscopic surgery or open lobectomy. systematic review and meta-analysis. Ann Thorac Surg 2021;111:302-13.

16. Yang CJ, Kumar A, Klapper JA, et al. A National Analysis of Long-term Survival Following Thoracoscopic Versus Open Lobectomy for Stage I Non-small-cell Lung Cancer. Ann Surg 2019;269:163-71.

17. Yang CJ, Kumar A, Deng JZ, et al. A national analysis of short-term outcomes and long-term survival following thoracoscopic versus open lobectomy for clinical stage II non-small-cell lung cancer. Ann Surg 2019. [Epub ahead of print]. doi: 10.1097/SLA.0000000000003231.

18. Yang W, Zhang G, Pan S, et al. Comparison of the perioperative efficacy between single-port and two-port video-assisted thoracoscopic surgery anatomical lung resection for non-small cell lung cancer: a systematic review and meta-analysis. J Thorac Dis 2019;11:2763-73.

19. Petersen RH, Hansen HJ. Learning curve associated with VATS lobectomy. Ann Cardiothorac Surg 2012;1:47-50.

20. Divisi D, Barone M, Zaccagna G, et al. Video-assisted thoracoscopic surgery lobectomy learning curve: what program should be offered in a residency course?. J Vis Surg 2017;3:143.

21. Cao C, Tian DH, Wolak K, et al. Cross-sectional survey on lobectomy approach (X-SOLA). Chest 2014;146:292-8.

22. Liu L, Mei J, He J, et al. International expert consensus on the management of bleeding during VATS lung surgery. Ann Transl Med 2019;7:712.

23. Medbery RL, Gillespie TW, Liu T, et al. Nodal Upstaging Is More Common with Thoracotomy than with VATS During Lobectomy for Early-Stage Lung Cancer: An Analysis from the National Cancer Data Base. J Thorac Oncol 2016;11:222-33.

24. Licht PB, Jorgensen OD, Ladegaard L, et al. A national study of nodal upstaging after thoracoscopic versus open lobectomy for clinical stage I lung cancer. Ann Thorac Surg 2013;96:943-9; discussion 949-50.

25. Hennon MW, DeGraaff LH, Groman A, et al. The association of nodal upstaging with surgical approach and its impact on long-term survival after resection of non-small-cell lung cancer. Eur J Cardiothorac Surg 2020;57:888-95.

26. Flores RM, Alam N. Video-assisted thoracic surgery lobectomy (VATS), open thoracotomy, and the robot for lung cancer. Ann Thorac Surg 2008;85:S710-S715.

27. Chen S, Huang S, Yu S, et al. The clinical value of a new method of functional lymph node dissection in videoassisted thoracic surgery right non-small cell lung cancer radical resection. J Thorac Dis 2019;11:477-87.

28. Chen B, Wang X, Yu X, et al. Lymph node metastasis in Chinese patients with clinical T1 non-small cell lung cancer: A multicenter real-world observational study. Thorac Cancer 2019;10:533-42.

29. Li X, Li X, Fu X, et al. Survival benefit of skip metastases in surgically resected N2 non-small cell lung cancer: A multicenter observational study of a large cohort of the Chinese patients. Eur J Surg Oncol 2020;46:1874-81.

30. Austin PC. Optimal caliper widths for propensity-score matching when estimating differences in means and differences in proportions in observational studies. Pharm Stat 2011;10:150-61.

31. Falcoz PE, Puyraveau M, Thomas PA, et al. Videoassisted thoracoscopic surgery versus open lobectomy for primary non-small-cell lung cancer: a propensitymatched analysis of outcome from the European Society of Thoracic Surgeon database. Eur J Cardiothorac Surg 2016;49:602-9.

32. Long H, Tan Q, Luo Q, et al. Thoracoscopic Surgery 
Versus Thoracotomy for Lung Cancer: Short-Term Outcomes of a Randomized Trial. Ann Thorac Surg 2018;105:386-92.

33. Wang Z, Pang L, Tang J, et al. Video-assisted thoracoscopic surgery versus muscle-sparing thoracotomy for non-small cell lung cancer: a systematic review and meta-analysis. BMC Surg 2019;19:144.

34. Gonfiotti A, Viggiano D, Voltolini L, et al. Enhanced recovery after surgery and video-assisted thoracic surgery lobectomy: the Italian VATS Group surgical protocol. J Thorac Dis 2018;10:S564-S570.

35. Guo C, Xia L, Mei J, et al. A propensity score matching study of non-grasping en bloc mediastinal lymph node dissection versus traditional grasping mediastinal lymph node dissection for non-small cell lung cancer by videoassisted thoracic surgery. Transl Lung Cancer Res 2019;8:176-86.

36. Yang CF, Sun Z, Speicher PJ, et al. Use and Outcomes of Minimally Invasive Lobectomy for Stage I Non-Small Cell Lung Cancer in the National Cancer Data Base. Ann Thorac Surg 2016;101:1037-42.

37. Cao C, Manganas C, Ang SC, et al. Video-assisted thoracic surgery versus open thoracotomy for non-small cell lung cancer: a meta-analysis of propensity scorematched patients. Interact Cardiovasc Thorac Surg 2013;16:244-9.

38. Pagès PB, Delpy JP, Orsini B, et al. Propensity Score Analysis Comparing Videothoracoscopic Lobectomy With Thoracotomy: A French Nationwide Study. Ann Thorac Surg 2016;101:1370-8.

39. Laursen LØ, Petersen RH, Hansen HJ, et al. Videoassisted thoracoscopic surgery lobectomy for lung cancer is associated with a lower 30-day morbidity compared

Cite this article as: $\mathrm{Xu} \mathrm{J}, \mathrm{Ni} \mathrm{H}, \mathrm{Wu} \mathrm{Y,} \mathrm{Cao} \mathrm{J,} \mathrm{Han} \mathrm{X,} \mathrm{Liu} \mathrm{L,}$ Fu X, Li Y, Li X, Xu L, Liu Y, Zhao H, Liu D, Peng X, Hu J. Perioperative comparison of video-assisted thoracic surgery and open lobectomy for pT1-stage non-small cell lung cancer patients in China: a multi-center propensity score-matched analysis. Transl Lung Cancer Res 2021;10(1):402-414. doi: $10.21037 /$ tlcr-20-1132 with lobectomy by thoracotomy. Eur J Cardiothorac Surg 2016;49:870-5.

40. Dziedzic R, Marjanski T, Binczyk F, et al. Favourable outcomes in patients with early-stage non-small-cell lung cancer operated on by video-assisted thoracoscopic surgery: a propensity score-matched analysis. Eur J Cardiothorac Surg 2018;54:547-53.

41. Bendixen M, Jørgensen OD, Kronborg C, et al. Postoperative pain and quality of life after lobectomy via video-assisted thoracoscopic surgery or anterolateral thoracotomy for early stage lung cancer: a randomised controlled trial. Lancet Oncol 2016;17:836-44.

42. Martin JT, Durbin EB, Chen L, et al. Nodal upstaging during lung cancer resection is associated with surgical approach. Ann Thorac Surg. 2016;101:238-44; discussion 44-5.

43. Boffa DJ, Kosinski AS, Paul S, et al. Lymph node evaluation by open or video-assisted approaches in 11,500 anatomic lung cancer resections. Ann Thorac Surg 2012;94:347-53.

44. Merritt RE, Hoang CD, Shrager JB. Lymph node evaluation achieved by open lobectomy compared with thoracoscopic lobectomy for N0 lung cancer. Ann Thorac Surg 2013;96:1171-7.

45. Batchelor TJP, Rasburn NJ, Abdelnour-Berchtold E, et al. Guidelines for enhanced recovery after lung surgery: recommendations of the Enhanced Recovery After Surgery (ERAS(R)) Society and the European Society of Thoracic Surgeons (ESTS). Eur J Cardiothorac Surg 2019;55:91-115.

(English Language Editor: R. Scott) 